\title{
Dynamic Simulation Methodology for Implementing Circular Economy: A New Case Study
}

\author{
Edna Guevara-Rivera (iD, Roberto Osorno-Hinojosa iD, Victor Zaldivar-Carrillo iD, Humberto Perez-Ortiz (iD \\ Western Institute of Technology and Higher Education (ITESO) (Mexico) \\ ednaguevara@iteso.mx,rosorno@iteso.mx,victorhugo@iteso.mx,hperezo@iteso.mx
}

Received: June 2021

Accepted: September 2021

\begin{abstract}
:
Purpose: Circular economy (CE) principles have evolved in response to natural resource depletion as a set of guidelines for eliminating the linear take-use-dispose model of product consumption. The consequences of shifting from a linear to a circular supply chain are difficult to visualize in the long term. This study aims to design a methodology for building a simulation model to implement CE strategies in any small and medium-sized enterprise SME to prove policies before implementing them in the real world. This paper applied the methodology in a biological cycle case study: a confectionery factory in Mexico.

Design/methodology/approach: This study evaluated service-dominant logic, ecosystem services, system dynamics, and agent-based modeling to design the proposed methodology. A series of interviews with stakeholders were performed to assess the simulation model during the development phase. The circular economy indicator prototype (CEIP) was used as a circular maturity measure of the confectionery factory. The simulator was executed in Netlogo software, implementing a four-scenario analysis based on two CE policies for the caramel recycling process. Five state variables were proposed in this analysis: confectionery waste, recycled glucose, recycling utilization, costs of recycled glucose, and profit.
\end{abstract}

Findings: The CEIP score of the confectionery factory was $52 \%$, rated as a "good" product. Regarding scenario analysis, the first scenario had the highest profit improvement.

Practical implications: The simulator allowed stakeholders to understand the operation of the recycling process and visualize all variables involved in the system.

Originality/value: In the CE literature, little attention has been paid to proposing a methodology for designing a simulation model to implement CE strategies in any industry. Thus, this study implements a nine-step methodology based on services context and dynamic simulation tools to design a platform to evaluate and visualize the consequences of CE strategies implementation in the long term.

Keywords: circular economy, simulation, confectionery, service-dominant logic; ecosystem-services, agent-based modeling, system dynamics

\section{To cite this article:}

Guevara-Rivera, E., Osorno-Hinojosa, R., Zaldivar-Carrillo, V., \& Perez-Ortiz, H. (2021). Dynamic simulation methodology for implementing circular economy: A new case study. Journal of Industrial Engineering and Management, 14(4), 850-862 https://doi.org/10.3926/jiem.3609 


\section{Introduction}

The current and traditional linear production system is unsustainable due to the traditional one-way (linear) throughput flow of materials and energy between nature and human economy. In response to this global sustainable issue, a circular economy aims to redefine growth by proposing a cyclical flow of materials and energy (Frosch \& Gallopoulos, 1989; Korhonen, Honkasalo \& Seppälä, 2018). However, the final outcome when transitioning from a linear to a circular supply chain system is not readily visible in the long term. For this reason, stakeholders fear investing in sustainable policies, and it is not easy to convince them (Korhonen et al., 2018). Following this premise, there are academic contributions related to the development of frameworks and simulators that support stakeholders during the decision-making process when implementing CE strategies within their organization. For example, Pieroni, McAloone and Pigosso (2019) developed a framework to implement business model innovations related to CE. Likewise, Lieder, Asif, Rashid, Mihelič and Kotnik (2017) combined agent-based (ABM) and discrete-event simulation (DES) models to develop a tool where the product's design and production were evaluated in different scenarios according to its carbon footprint. Furthermore, DES and system dynamics (SD) theory are used to develop a simulation model that helps identify a correct CE strategy, that is to say, when to upgrade, refurbish, remanufacture, or recycle the desired product (Charnley, Tiwari, Hutabarat, Moreno, Okorie \& Tiwari, 2019). In this sense, (Guevara-Rivera, Osorno-Hinojosa \& Zaldivar-Carrillo, 2018) designed a hybrid services simulation model (HSSM), which is a nine-step methodology for designing a simulation tool to prove several circular policies before their implementation in the real world. This methodology is based on four perspectives: service-dominant logic (Vargo \& Lusch, 2004), ecosystem services (Matthies, D’Amato, Berghäll, Ekholm, Hoen, Holopainen et al., 2016), agent-based modeling (Wooldridge, 2009), and system dynamics theory (Forrester, 1997).

The Ellen MacArthur Foundation (EMAF) classified the flow of materials through the supply chain into two different cycles: biological and technical (EMAF, 2021). Regarding biological cycles, EMAF published a report related to food systems and their performance in big cities. In this paper, authors explain why the current feeding systems are no longer sustainable. There are several causes that can be attributed to the substantial quantities of food waste generated by large cities, including food production processes that are harmful to humans, as well as the long distances between food production sites and cities that increase the food surplus and packing. Addressing these problems, MAF proposes three objectives that cities can accomplish to catalyze a circular economy for food: (1) source food is grown regeneratively and locally where appropriate, (2) make the most of food, and (3) design and produce healthier food products (EMAF, 2019).

Moreover, the food industry may not be producing enough nutritious food for the growing global population, leading to alterations in the overall nutritional needs (Tilman, Cassman, Matson, Naylor \& Polasky, 2002). Besides, challenges like water scarcity, energy use, and land availability need to be addressed to transform a food system into a healthy, nutritious, and environmentally sustainable practice (Miah, Griffiths, McNeill, Halvorson, Schenker, Espinoza-Orias et al., 2018; UNESCO, 2020; Flammini, Puri, Pluschke \& Dubois, 2014).

In regards to the food sector, the methodology proposed by Guevara-Rivera et al. (2018) was implemented in a food bank as a case study (Guevara-Rivera, Osorno-Hinojosa \& Zaldivar-Carrillo, 2020). From this implementation, the study group concluded that in this industry, even though it behaves like a value chain, food processes are complex and different compared to regular products. This complexity varies depending on the food production stage, from farming and collection, to the final disposal. The confectionery sector is not the exception. The challenges faced by food processes are important in the connection between nutrition, health, and environmental issues (Tilman et al., 2002). On this basis, the increasing consumption of confectionery products is pressuring the supply chains across the globe. For example, cocoa and palm oil are only grown in certain parts of the world (Miah et al., 2018) and in 2018, Mexico was the second place in confectionery consumption in Latin America and the sixth place in the world with an estimated consumption per capita of $4.5 \mathrm{~kg}$ per year (Confitexpo, 2021).

Since confectionery products are diverse, the entire supply chain is complex like raw material supply, specialized equipment acquisition, tasty and nutritious recipe design, product packing, commercialization strategies, and the 
final disposal of confectionery products. A system-view approach across the confectionery supply chain is required from raw material use to the final disposal, considering a cradle to grave assessment to attend the transition towards environmental sustainability (Miah et al., 2018). In the European Union, there is a significant growth in the confectionery waste valorization, for example, the production of bioethanol and biogas as bioenergy products and bio-based and biodegradable polymers (Harrison, Johnstone-Robertson, Rademeyer, Murhonyi, Ngwenya, Horn et al., 2019).

Therefore, the aim of this study was to assess service-dominant logic, ecosystem services, system dynamics, and agent-based modeling to design a methodology for a simulation model implemented in a Mexican small and medium-sized enterprise (European Comission, 2021), particularly in a confectionery factory with a value chain configuration within its business model.

First, we describe an overview of the four perspectives employed for developing the proposed nine-step methodology. Next, we explain, step by step, the methodology implementation in the caramel recycling process of the confectionery and the results are described. Finally, we discuss an overview of the outcomes delivered by the simulator like the four-scenario analysis.

\section{Literature Review}

Circular Economy (CE) is an economy of systems composed by society, production, and consumption that maximize services produced from the flow of material and energy across the supply chain using five principles: design out waste, build resilience through diversity, work towards using energy 84 from renewable sources, think in systems, and think in cascades (Korhonen et al., 2018; Webster, 2017). Beyond these principles, for the real-life implementation of $\mathrm{CE}$, environmental, economic, and social limitations need to be considered. One of these limitations consists of the strategic management used for internal vs. external policies around the organization. In other words: "How can an individual firm convince its stakeholders, customers, and authorities that its strategy of waste maximization is beneficial for the environment and sustainability?" (Korhonen et al., 2018).

\subsection{Circular Economy Indicator Prototype (CEIP)}

The impact of CE implementation in an industry is difficult to quantify and visualize. According to Saidani, Cluzel, Leroy and Yannou (2019), monitoring circularity performance is a challenging task due to the dynamic nature of CE. In the literature, several instruments evaluate and quantify the level of engagement and product performance of CE principles (WBCSD, 2021; MacArthur, 2015; Potting, Hekkert, Worrell \& Hanemaaijer, 2017; Saidani, Yannou, Leroy \& Cluzel, 2017; Cayzer, Griffiths \& Beghetto, 2017) All of these instruments involve several stages of a supply chain: design, materials, manufacturing, packing, delivery, and the final user. The Circular Economy Indicator Prototype (CEIP) contains fifteen questions that evaluate five cycle stages of a circular supply chain: design, manufacturing, commercialization, in use, and end of use. Each question associates a measurable variable with a CE principle using a weighted score. Some of these principles are dematerialization, effective packaging, energy from renewable resources, product warranty, waste reduction, and rental schemes, among others (Cayzer et al., 2017)

\subsection{The Four Perspectives}

The simulation modeling methodology implemented in this study is based on four perspectives: service-dominant logic, ecosystem services, agent-based modeling, and system dynamics. These concepts have emerged during the past 50 years. Service-dominant logic and ecosystem services study the co-creation of value between individuals and the environment. On the other hand, system dynamics and agent-based modeling model the interaction of the systems' elements with their own environment. The conjunction of these tools allowed us to design a methodology for developing a dynamic simulation model.

Vargo and Lusch (2004) defined service-dominant logic (SDL) as the source of value in a service ecosystem, which consists of "the activities emanating from specialized knowledge and the abilities that people provide for themselves and others (i.e., service, applied abilities) rather than the goods". In other words, the business 
environment uses the term ecosystem as "networked constellations of firms, often centered on a central actor" (Vargo \& Lusch, 2008). In a recent article, they propose future research concerning SDL from different perspectives, such as dynamic strategy development, complexity economics, genetic algorithms to understand complex service ecosystems, and environmental sustainability through service ecosystem viability and resiliency (Vargo \& Lusch, 2017).

Value creation by a service system is a non-linear interactive and dynamic process. The result of this process is a potential value that various other actors, processes, and resources, which are part of a service system's worth network, can utilize, miss, or destroy (i.e., a forest). From this definition, Matthies et al. (2016) describe the role of the natural ecosystem as a service system that provides resources with potential value and a service-dominant value creation network within a socio-ecological system is proposed. In other words, ecosystem services (ES) can be viewed as a service system where actors are living beings (i.e., a forest or a lake), which supply resources with a potential value that human beings can create or destroy them.

On the other hand, the system theory intends to explain the dynamic and complex individual interactions as a whole. A system modeled as a collection of autonomous decision making entities or agents is known as the agentbased modeling (ABM) system. Each agent individually assesses the situation and makes decisions based on a set of rules and the interaction with other agents and the surrounding environment to meet objectives (Wooldridge, 2009; Bonabeau, 2002; Hesan, 2016; Swinerd \& McNaught, 2012). Otherwise, system dynamics (SD) theory takes a continuous-time approach and constructs models with differential equations, representing state variables as stocks or level variables, and exchange rates variables as flows into or out of stocks that are continuous or discrete time points (Forrester, 1997; Sterman, 2000). A computer-aided approach is used for policy analysis and design in any dynamic system (social, managerial, economic, or ecological), and is characterized by interdependence, mutual interaction, information feedback, circular causality, and further analyzed by reinforcement (R) and balance (B) loops (System Dynamics Society, 2021).

\section{Methodology}

In this research, we replicated the aforementioned methodology known as Hybrid Services Simulation Model (HSSM) for the CE implementation (Guevara-Rivera et al., 2018) in a second case study of the food sector: a confectionery factory. We selected this confectionery factory for four important reasons: (1) it is a Mexican small and medium-sized enterprise (SME) with around 200 employees, (2) its business model has a value chain configuration (Porter, 2001), (3) there is available data for the simulation model, and (4) there is a confectionery recycling process to reuse glucose from the waste of the manufacturing process.

To develop this methodology, we conducted a series of visits and interviews with employees involved in the confectionery process to understand how it works. At the beginning of this study, the confectionery factory recycled waste caramel as syrup to be reintroduced into the main process. However, the process owners were considering the possibility of removing this recycling process as it was perceived as an expense rather than a benefit. After assessing this situation, we proposed several variables to evaluate the feasibility of the recycling process implementation in the confectionery sector, such as production cost, utilization, break-even point, and circularity index of the recycling process. The simulation model obtained from the methodology implemented in the confectionery factory mainly evaluated CE strategies according to the case study, and it also calculated the previously described variables. The stakeholders' involvement was critical for the simulation model development process.

The methodology proposed establishes nine steps for circular economy (CE) implementation in a simulation model (Figure 1). Previous work considers the first four stages, and the next five steps are those proposed by the modeling process for system dynamics (Sterman, 2000). An extensive explanation of each step during the development and the implementation in a food bank in Guadalajara, Mexico, are depicted by Guevara-Rivera et al. (2018). Next, as results, we describe the implementation process in the confectionery factory. 

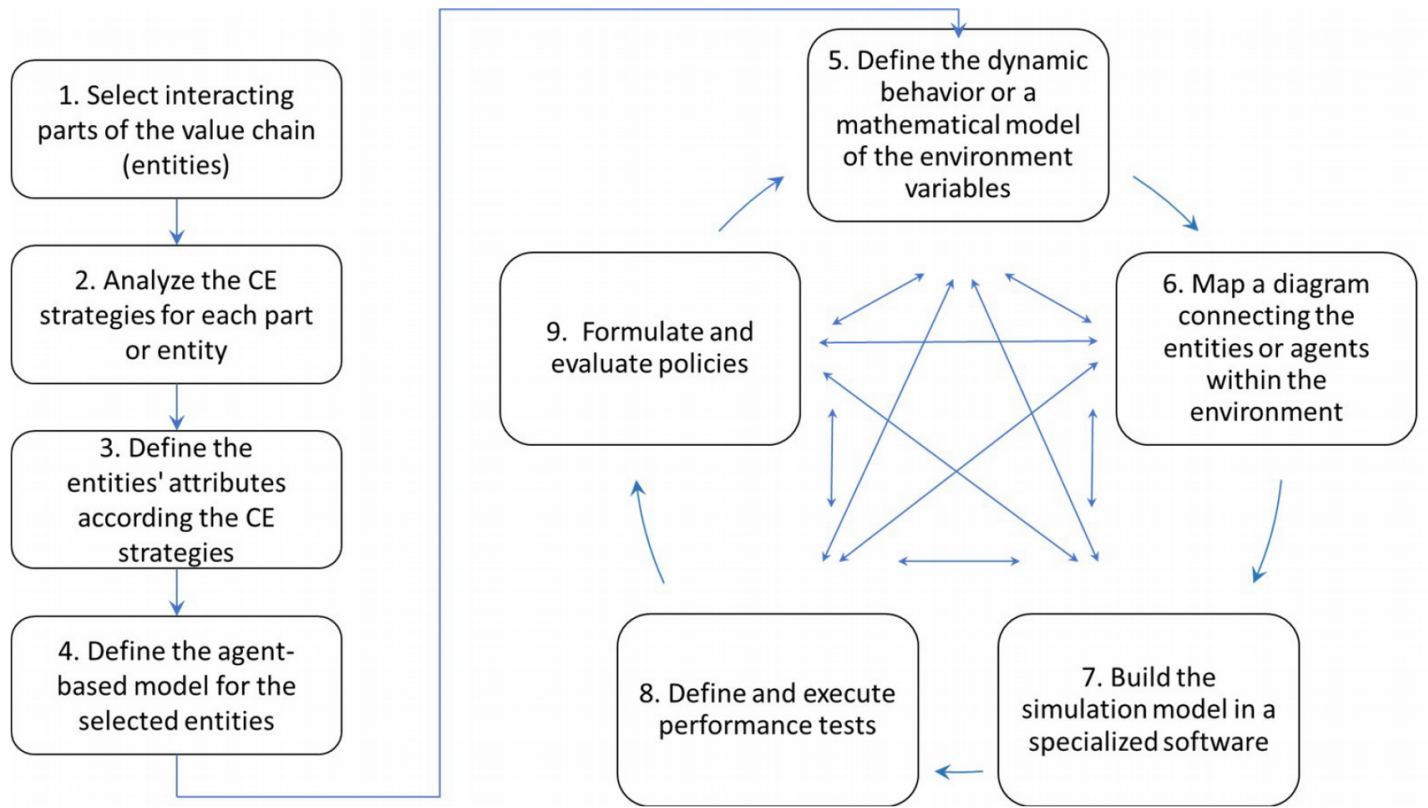

Figure 1. Methodology proposal for implementing a hybrid service simulation model for the circular economy

\section{Results}

In this section, we describe the development of the methodology proposed in the confectionery case study. In each subsection, there is a detailed explanation of the step implemented.

\subsection{Selection of Interacting Value Chain Components}

According to EMAF (2021), confectionery product manufacturing is classified as a biological cycle because the main raw material is sugar and the final product is edible. As CE considers the entire supply chain from the production of raw materials to the final disposal, we compared the supply chain of our company to the one explained by Miah et al. (2018) who establishes six main stages: raw materials, preprocessing (only for chocolate-based products), manufacturing, distribution and retail, consumption, and disposal. The latter two stages belong to the final user, and the other four to the confectionery manufacturer. Regarding raw materials, there are two categories: ingredients and packaging, which are inputs to the preprocessing and manufacturing processes (Miah et al., 2018).

In this step, we applied the CEIP instrument to our case study (Cayzer et al., 2017). We adjusted the instrument according to the product's nature. The confectionery factory only covered three from the five life cycle stages that CEIP evaluates: design, manufacture, and commercialization. Within these elements, there are two questions that we did not consider for the evaluation: (i) "Q2: Is the product lighter than its previous version?" and (ii) "Q8: Is there a rental option for the product?". So, we eliminated their contribution in the final score, and it was calculated as shown in Table 1 . The product rating was $52 \%$, which corresponds to a "good" product ranking according to the CEIP scale.

From this evaluation, we compared the life cycle stages with those proposed by Kalmykova, Sadagopan, and Rosado (2018). We chose four phases: material sourcing, design, manufacturing, and recycling and recovery. We analyzed these strategies related to the life cycle stages in step 2.

\subsection{Analysis of the CE Strategies}

In this step, we analyzed all the strategies that Kalmykova et al. (2018) proposed for each stage. We evaluated each stage according to the following criteria: (1) if there were strategies related to the food industry, and (2) if the strategies were already implemented in the case study. 


\begin{tabular}{|c|c|c|c|c|}
\hline Life cycle & Question & Answer & Scored & Rating \\
\hline \multirow{3}{*}{ Design/Redesign } & Q1: Is the product made from recycle or reused material? (20p) & $10 \%$ & 1 & \multirow{3}{*}{$6 / 25=24 \%$} \\
\hline & Q2: Is the product lighter than its previous version? (2p) & - & - & \\
\hline & $\begin{array}{l}\text { Q3: Is there a complete bill of materials and substances for the } \\
\text { product? }(5 p)\end{array}$ & Yes & 5 & \\
\hline \multirow{2}{*}{ Manufacture } & $\begin{array}{l}\text { Q4: Is there a complete bill of energy for the manufacturing } \\
\text { process? (10p) }\end{array}$ & Yes & 10 & \multirow{2}{*}{$25 / 25=100 \%$} \\
\hline & $\begin{array}{l}\text { Q5: Is there a complete bill of solid waste for the } \\
\text { manufacturing process? (15p) }\end{array}$ & Yes & 15 & \\
\hline \multirow{3}{*}{ Commercialisation } & Q6: What packaging is being used? (5p) & Recyclable & 1 & \multirow{3}{*}{$3 / 15=20 \%$} \\
\hline & Q7: What is the product's warranty? (10p) & $2-3$ year & 1 & \\
\hline & Q8: Is there a rental option for the product? (15p) & - & - & \\
\hline
\end{tabular}

Table 1. CEIP instrument applied to the confectionery factory (Cayzer et al., 2017)

Particularly, we observed the high-quality recycling strategy, which refers to the recovery of materials in pure form without contamination and that belong to the material sourcing stage. In the case study, the confectionery factory has a recycling process of glucose from the confectionery waste generated during the manufacturing process. The second strategy observed is material productivity, which refers to the amount of economic value generated by a unit of material input or material consumption (OECD, 2021). This strategy belongs to the manufacturing process and is related to the high-quality recycling strategy due to recycled glucose is used in the manufacturing process. The resulting selected stages were materials sourcing and manufacturing, according to Kalmykova et al. (2018).

From the strategies analyzed, the indicators used in the simulation model are those that explain the strategy. For the first strategy, high-quality recycling, we proposed confectionery waste, recycled glucose production, and cost of recycled glucose, all in kilograms per day. For the second strategy entitled material productivity, we proposed the break-even point and recycling process utilization. We understand by break-even point (Qe) as the volume of product sales when the utility is zero (Prakash-Singh \& Deshpande, 1982). In the case study, these indicators help stakeholders evaluate the feasibility of the recycled glucose production.

To calculate the break-even point see equation 1, where $\mathrm{P}$ is the sales price per unit, VC is the variable cost, TFC is the total fixed cost, $\mathrm{Q}$ is the quantity of products that is sold by an organization, and CM is the contribution margin.

$$
\mathrm{Qe}=\mathrm{TFC} /(\mathrm{P}-\mathrm{VC})=\mathrm{TFC} / \mathrm{CM}
$$

\subsection{Entities' Attributes According to CE Strategies}

First, the inputs and outputs of the stages selected in the previous step were defined. Then, the units of measurement were determined in conjunction with the people involved in the industry. Lastly, we obtained a list of the variables from each process: manufacturing and confectionery recycling (Figure 2). These variables were used in step seven for implementing the simulation model in a specialized software.

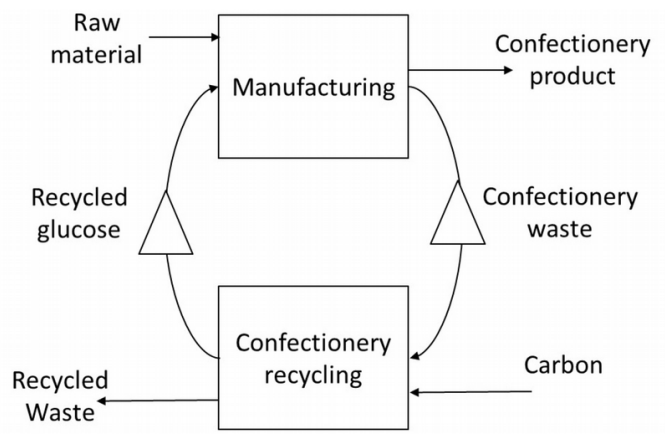

Figure 2. Confectionery factory processes connected with I/O variables 


\subsection{Agent-Based Model for Selected Entities}

The fourth step is to define the agent-based model that is related to the entities or processes selected using the Modeling Agent systems based on the Institutional Analysis (MAIA) meta-model (Ghorbani, Dijkema, Bots, Alderwereld \& Dignum, 2014). In this context, we found that the MAIA model is useful for defining the agent model and its actions in different structures. In our case study, we analyzed three agents: quality inspector, product engineer, and operations director. Each agent makes different decisions concerning the selected processes. These decisions affect the processes performance and consequently, the variables defined in the previous step. For example, the activation of the confectionery recycling process is determined by confectionery waste stock and the need to recycle glucose. In every agent model it is important to define the physical component in which agents make decisions. Particularly, in this case study, the physical component refers to the confectionery product.

\subsection{Dynamic Behavior of the Environment Variables}

In this step, the dynamic behavior using a causal diagram was defined (Figure 3). We found two reinforcement (R1 and R2) and two balance (B1 and B2) loops. The R1 loop involves the two processes: manufacturing together with recycling and both processes increase their production if one of them rises. The R2 loop refers to the use of coal. If the production of recycled glucose increases, more coal is needed. In the B1 loop, the use of glucose is affected by recycled glucose. If there is more recycled glucose, then less quantities of glucose are used as raw material. Finally, the B2 loop associates the cost of the coal necessary to produce recycled glucose. If the cost of coal increases, so does the recycling process costs and this causes a decline in the production of recycled glucose.

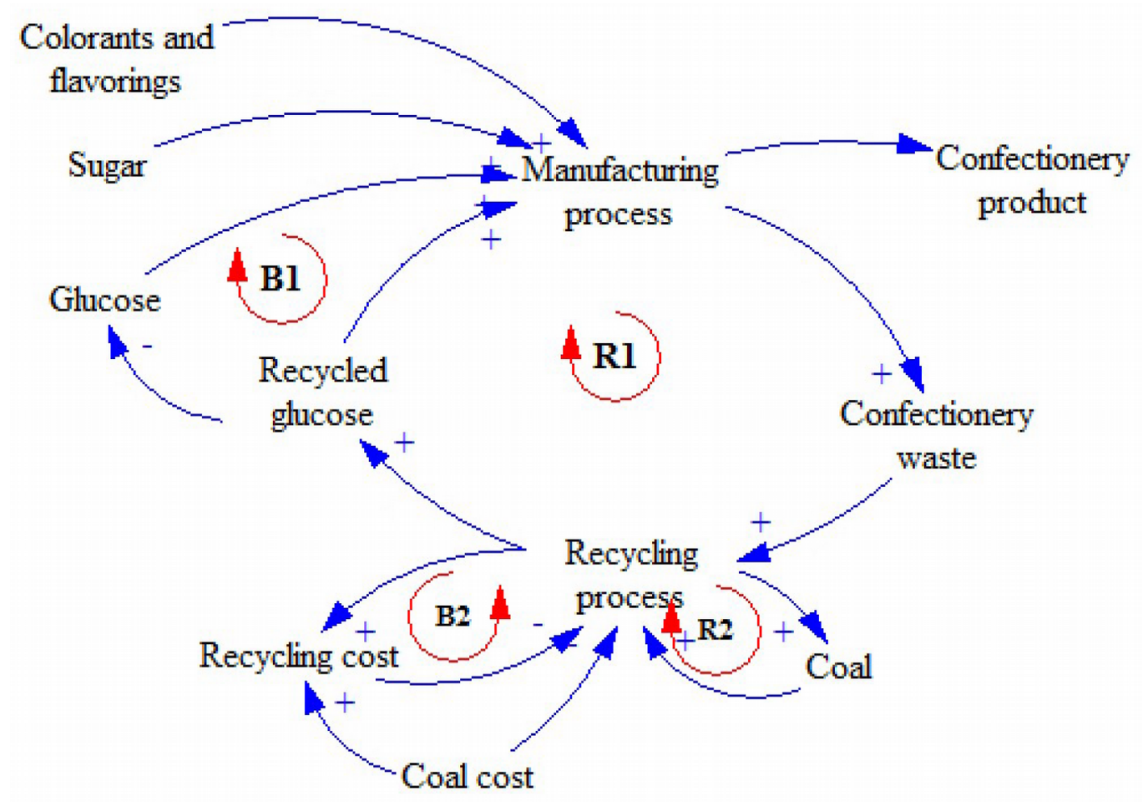

Figure 3. Dynamic behavior of the confectionery case study

\subsection{Entities Connection Diagram}

It is important to locate the agents' actions in the physical structure. This step facilitates programming the model in the software. We defined three agents in step 4: the quality inspector, product engineer, and operations director. The quality inspector decides the waste quantity according to the quality yield of the confectionery product. The product engineer determines the quantity of recycled glucose used in confectionery manufacturing. The operations director determines when to recycle glucose, taking into consideration the cost of raw materials like sugar, glucose, and coal. 


\subsection{Simulation Model Implementation in a Software}

To program the model, we used Netlogo version 6.0.4. This software allows the combination of system dynamics (SD) and agent-based modeling (ABM) simulation models. Besides, it allows building a final user interface to modify the inputs and parameters in order to observe the behavior of the outputs. We built the model from the previous steps and modeled a system using flow and level variables as SD theory suggests. We identified four-level variables or stocks in the model: manufacturing, confectionery waste, recycling production, and recycled glucose. In the manufacturing process, the input flows are raw material: glucose, sugar, water, and recycled glucose. The manufacturing's output flows are the confectionery product and the confectionery waste (i.e., the product that does not meet quality standards).

In our case study, the confectionery waste was stored as stock until it was required by the recycling process. Once obtained, the recycled glucose was also stored until the manufacturing process required recycled caramel to produce confectionery (Figure 4).



Figure 4. System dynamics model of the confectionery case study

\subsection{Performance Test Execution}

We executed the performance tests defined by Sterman (2000), and Railsback and Grimm (2019) to calibrate the model. The manufacturing process is pulled by demand, which is around $400 \mathrm{~kg} / \mathrm{hr}$. As the confectionery waste is a portion of the production (around 4\%), its behavior is proportional. The recycling process is not operating all the time because its execution depends on three variables: (1) if there is enough confectionery waste to load the recycling machine, (2) if the recycled glucose cost is less than normal glucose, and (3) if there is no recycled glucose in stock. These conditions make the system behavior oscillate and recycling production can operate only to $25 \%$ capacity (Figure 5). Graph 5a shows that when the recycled glucose is produced, the manufacturing production increases, next in graph $5 \mathrm{~b}$ shows the behavior of confectionery waste and recycled glucose stocks, and finally, graph $5 \mathrm{c}$ describes the profit calculated from the price of the raw material and recycling total costs. 


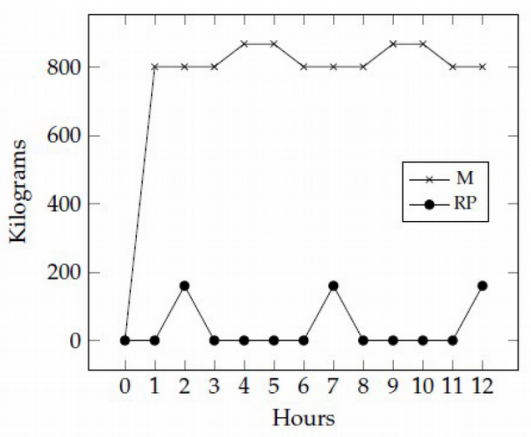

(a)

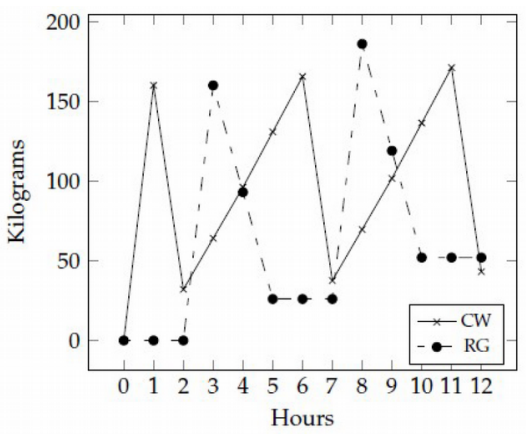

(b)

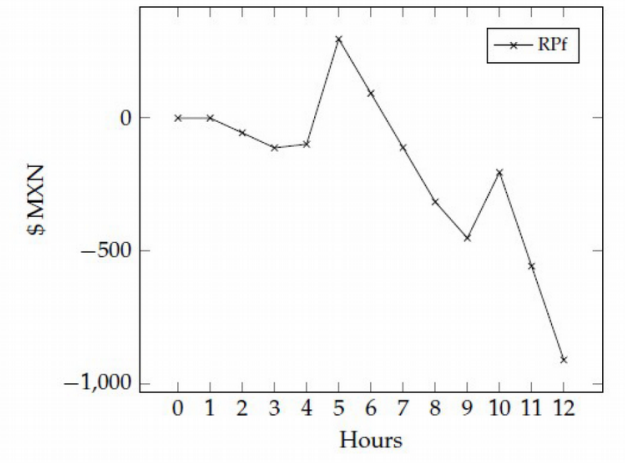

(c)

Figure 5. Performance of main variables in the hybrid simulation model: (a) Manufacturing (M) vs. Recycling production (RP) processes. (b) Confectionery waste (CW) vs. recycled glucose (RG) stocks. (c) Recycling profit (RPf)

\subsection{Policy Formulation and Evaluation}

According to the four perspectives proposed for assessing CE, we formulated policies that comply with CE principles based on service-dominant logic (SDL) and ecosystem services (ES) theories. Evaluating the strategies analyzed in step one and the results obtained in step eight, we proposed two policies: (i) marketing the recycled glucose; and (ii) obtaining confectionery waste from other industries to increase the recycling production. We evaluated both policies in four scenarios according to the utilization rate of the recycling process. The first scenario entitled "low input, low output" supposed that the there was a low amount of waste from other factories and a low sale of recycled glucose. The second scenario "low input, high output" presumed that the waste acquired from other industries was low, but the recycled glucose sales were high. The third scenario entitled "high input, low output" estimated that the waste received was low, but the sales of recycled glucose were high. Finally the fourth scenario, called "high input, high output", estimated for the acquisition of waste and recycled glucose sales were high (Figure 6).

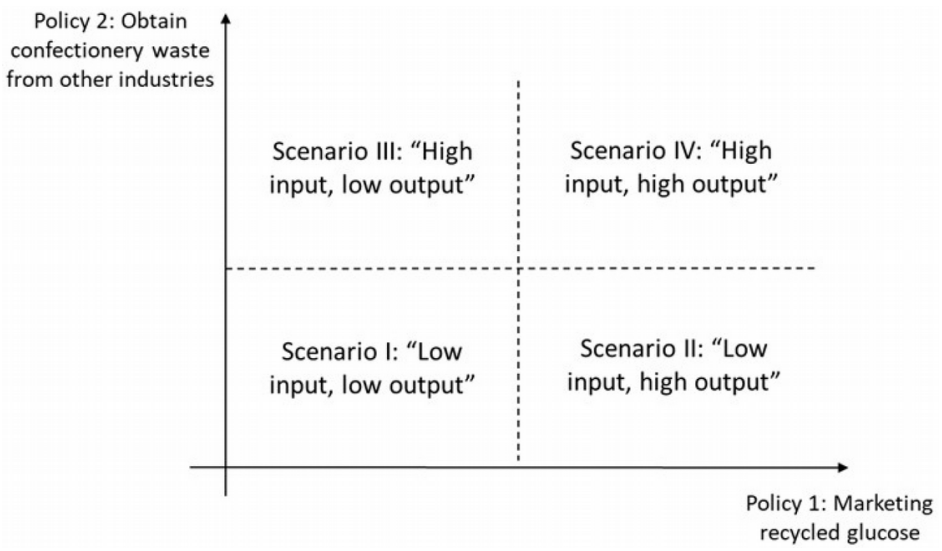

Figure 6. Four scenarios proposed from two policies 
Several variables were proposed to evaluate the feasibility of the recycling operation as a separate business unit from the main process. These variables are confectionery waste, recycling glucose production, cost of recycled glucose, break-even point (Qe), recycling process utilization, and benefits. We compared these variables in the scenarios proposed (Table 2). Thus, the first scenario had the highest benefits due to the cost of recycling glucose, and the recycling process utilization was $42 \%$ capacity. In contrast, the third scenario had the lowest benefits and the highest cost of recycled glucose due to the high confectionery waste quantity received from other industries and low sales, causing the recycling utilization were at 100\% capacity (Figure 7).

The user determines the recycled glucose price. In the simulation results shown in Figure 7, we considered the recycled glucose price equal to the cost of raw material, so that the use of recycled caramel could be viable. If the sale price of recycled glucose increases, the benefits of the four scenarios also increase.

\begin{tabular}{|c|c|c|c|c|}
\hline \multirow{2}{*}{ Confectionery waste } & \multicolumn{4}{|c|}{ Scenarios } \\
\cline { 2 - 5 } & I. LI, LO & II. LI, HO & III. HI, LO & IV. HI, HO \\
\hline Recycled glucose & $83.16 \mathrm{~kg}$ & $91.2 \mathrm{~kg}$ & $4,773.88 \mathrm{~kg}$ & $4,773.88 \mathrm{~kg}$ \\
\hline Recycling utilization & $800 \mathrm{~kg}$ & $800 \mathrm{~kg}$ & $1760 \mathrm{~kg}$ & $1760 \mathrm{~kg}$ \\
\hline Cost recycled glucose & $42 \%$ & $42 \%$ & $100 \%$ & $100 \%$ \\
\hline Benefits & $\$ 6,448.29$ & $\$ 8,081.34$ & $\$ 26,079.27$ & $\$ 19,489.77$ \\
\hline
\end{tabular}

Table 2. Variables observed in the proposed scenarios

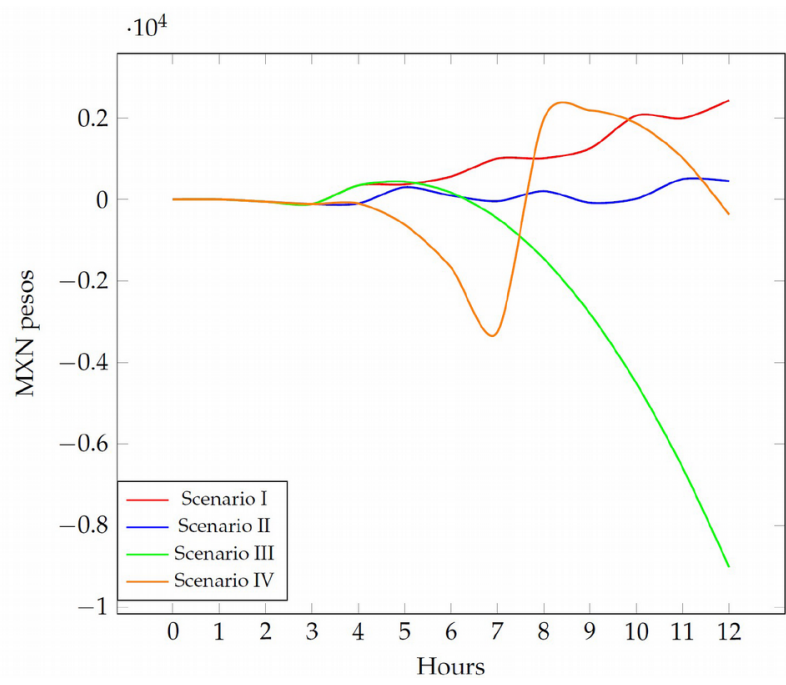

Figure 7. Profit performance from the four scenarios related to the two

policies: marketing recycled glucose and obtaining confectionery waste

\subsection{Model Validation}

Finally, we performed a series of interviews with recycling process decision-makers (operation manager, recycled-process owner, and quality manager) during the methodology implementation. At the end of the procedure, a questionnaire was presented and their feedback recorded. Key elements from the questionnaire were:

- Model purpose: the model allowed participants to understand the process behavior and all their interactions. Furthermore, they identified the variables and factors that influence the entire process and how they are related. 
- Model results: the model let shareholders know the recycling process costs more exactly because the calculus was based on activity costing and not only on average costs.

- Circular economy view: the operational manager attempted to minimize the usage of the recycling process before the simulator implementation. However, after evaluating the results obtained like costs and utilization; he decided to review the recycling process operation.

- User interface: the user interface was redesigned to be more friendly and understandable for the process owners to facilitate access to the input and output variables.

- Simulator usage: the shareholders considered outsourcing the model design service with a simpler user interface for daily planning during the operational process, not only for measuring the economy circular impact, but also in other business variables.

\section{Discussion and Conclusions}

The main contribution of this research is the conjunction of four techniques: service-dominant logic (SDL), ecosystem services (ES), agent-based modeling (ABM), and system dynamics (SD) for designing a simulation modeling methodology to replicate CE strategies. Unlike Pieroni et al. (2019) and Charnley et al. (2019), this paper presents the steps of the methodology implemented in a confectionery factory as a case study. In Mexico, there is no comparable work that involves circular economy in the confectionery industry. Simulation models are not a common practice in small and medium-sized enterprises, however, with the feedback obtained from process owners of the confectionery case study, we ascertained that simulators are beneficial in the daily business processes and the circular economy evaluation.

As SDL and ES suggest, the methodology was designed to find a co-creation value between the main actors (i.e., stakeholders and environment) involved in the ecosystem. The case study implementation demonstrated through the four-scenario analysis that an economic benefit for the stakeholders could exist if the recycled glucose was commercialized. Regarding the environment, the caramel waste disposed in landfills could be reduced.

Since the simulation model was developed using ABM and SD simulation methods, which the understanding of the system behavior and performance is one of their main objectives, we found that in addition to evaluating circular economy strategies, the simulator allowed partners to understand the operation of the recycling process and visualize all the variables involved in the system.

As future work, we first propose the design of a circular maturity instrument to measure the impact of the biological cycles in three aspects: economical, social, and environmental. Second, the implementation of the methodology proposed in other case studies to generalize its adoption. Third, the design of a process to outsource the methodology as a service focused on obtaining improved benefits for all the actors involved.

\section{Declaration of Conflicting Interests}

The authors declared no potential conflicts of interest with respect to the research, authorship, and/or publication of this article.

\section{Funding}

This work was supported in part by CONACYT (Consejo Nacional de Ciencia y Tecnología, Mexican Government) through the recognition granted to the PhD. Program in Engineering Sciences at ITESO.

\section{References}

Bonabeau, E. (2002). Agent-based modeling: Methods and techniques for simulating human systems. Proceedings of the national academy od sciences, 99, 7280-7287. https:// doi.org/10.1073/pnas.082080899

Cayzer, S., Griffiths, P., \& Beghetto, V. (2017). Design of indicators for measuring product performance in the circular economy. International Journal of Sustainable Engineering, 10, 289-298.

https://doi.org/10.1080/19397038.2017.1333543 
Charnley, F., Tiwari, D., Hutabarat, W., Moreno, M., Okorie, O., \& Tiwari, A. (2019). Simulation to enable a data-driven circular economy. Sustainability, 11(12), 3379. https://doi.org/10.3390/su11123379

Confitexpo (2021). Confitexpo Informa. Available at: https://www.confitexpoinforma.com/2019/11/12/cual-es-el-escenario-de-los-dulces-tipicos-mexicanos-actualmente/

EMAF (2019). Cities and Circular Economy for Food. Ellen MacArthur Foundation.

EMAF (2021). Ellen MacArthur Foundation. Available at: https://www.ellenmacarthurfoundation.org/circulareconomy/concept

European Comission (2021). SME Definition. Available at: https://ec.europa.eu/growth/smes/sme-definition en

Flammini, A., Puri, M., Pluschke, L., \& Dubois, O. (2014). Walking the nexus talk: assessing the water-energy-food nexus in the context of the sustainable energy for all initiative. Rome: FAO.

Forrester, J.W. (1997). Industrial dynamics. Journal of the Operational Research Society, 48(10), 1037-1041. https://doi.org/10.1057/palgrave.jors.2600946

Frosch, R.A., \& Gallopoulos, N.E. (1989). Strategies for manufacturing. Scientific American, 144-153. https://doi.org/10.1038/scientificamerican0989-144

Ghorbani, A., Dijkema, G., Bots, P., Alderwereld, H., \& Dignum, V. (2014). Model-driven agent-based simulation: Procedural semantics of a MAIA model. Simulation Modelling Practice and Theory, 49, 27-40.

https://doi.org/10.1016/j.simpat.2014.07.009

Guevara-Rivera, E., Osorno-Hinojosa, R., \& Zaldivar-Carrillo, V.H. (2018). Hybrid service simulation model for circular economy implementation. Proceedings of the 9th International Congress on Environmental Modelling and Software. Forth Collins, USA.

Guevara-Rivera, E., Osorno-Hinojosa, R., \& Zaldivar-Carrillo, V. H. (2020). A simulation methodology for circular economy implementation. Proceedings of the10th International Conference on Advanced Computer Information Technologies (ACIT). Deggendorf, Germany.

Harrison, S., Johnstone-Robertson, M., Rademeyer, S., Murhonyi, L., Ngwenya, C., Horn, C. et al. (2019). Value recovery from Solid Confectionery Waste. University of Cape Town, Centre for Bioprocess Engineering Research. Cape Town.

Hesan, R. (2016). Multi-methodology Modeling to Support Policy Analysis in Socio-technical Systems. Italy: University of Palermo.

Kalmykova, Y., Sadagopan, M., \& Rosado, L. (2018). Circular economy-From review of theories and practices to development of implementation tools. Resources, Conservation and Recycling, 135, 190-201. https://doi.org/10.1016/j.resconrec.2017.10.034

Korhonen, J., Honkasalo, A., \& Seppälä, J. (2018). Circular economy: the concept and its limitations. Ecological economics, 37-46. https://doi.org/10.1016/j.ecolecon.2017.06.041

Lieder, M., Asif, F.M., Rashid, A., Mihelič, A., \& Kotnik, S. (2017). Towards circular economy implementation in manufacturing systems using a multi-method simulation approach to link design and business strategy. The International Journal of Advanced Manufacturing Technology, 93(5), 1953-1970. https://doi.org/10.1007/s00170-017-06109

MacArthur, E. (2015). Circularity indicators: An approach to measuring circularity. Methodology.

Matthies, B.D., D’Amato, D., Berghäll, S., Ekholm, T., Hoen, H.F., Holopainen, J. et al. (2016). An ecosystem service-dominant logic?-integrating the ecosystem service approach and the service-dominant logic. Journal of Cleaner Production, 124, 51-64. https://doi.org/10.1016/j.jclepro.2016.02.109

Miah, J.H., Griffiths, A., McNeill, R., Halvorson, S., Schenker, U., Espinoza-Orias, N.D. et al. (2018). Environmental management of confectionery products: Life cycle impacts and improvement strategies. Journal of cleaner production, 177, 732-751. https://doi.org/10.1016/j.jclepro.2017.12.073 
OECD (2021). Material productivity. https://doi.org/10.1787/dae52b45-en

Pieroni, M.P., McAloone, T.C., \& Pigosso, D.C. (2019). Business model innovation for circular economy and sustainability: A review of approaches. Journal of cleaner production, 215, 198-216.

https://doi.org/10.1016/j.jclepro.2019.01.036

Porter, M.E. (2001). The value chain and competitive advantage. Understanding business processes, 50-66.

Potting, J., Hekkert, M., Worrell, E., \& Hanemaaijer, A. (2017). Circular economy: measuring innovation in the product chain. Netherlands: PBL Publishers.

Prakash-Singh., S., \& Deshpande, J.V. (1982). Break-Even Point. Economic and Political Weekly, 17(48), M123-M128.

Railsback, S., \& Grimm, V. (2019). Agent-based and individual-based modeling: a practical introduction. Princeton university press.

Saidani, M., Cluzel, F., Leroy, Y., \& Yannou, B. (2019). Testing the robustness of circularity indicators: empirical insights from workshops on an industrial product. Proceedings of the Design Society: International (3401-3410). Cambridge University Press. https://doi.org/10.1017/dsi.2019.347

Saidani, M., Yannou, B., Leroy, Y., \& Cluzel, F. (2017). Hybrid top-down and bottom-up framework to measure products' circularity performance. Proceedings of the 21th International Conference on Engineering Design (ICED). Vancouver, Canada.

Sterman, J.D. (2000). Business dynamics: systems thinking and modeling for a complex world. McGraw-Hill.

Swinerd, C., \& McNaught, K. (2012). Design classes for hybrid simulations involving agent-based and system. Simulation Modelling Practice and Theory, 25, 118-133. https://doi.org/10.1016/j.simpat.2011.09.002

System Dynamics Society (2021). From What is System Dynamics? Available at: https://systemdynamics.org/what-is-system-dynamics/

Tilman, D., Cassman, K., Matson, P., Naylor, R., \& Polasky, S. (2002). Agricultural sustainability and intensive production practices. Nature, 418, 671-677. https://doi.org/10.1038/nature01014

UNESCO (2020). The United Nations world water development report 2020: water and climate change. Available at: https://unesdoc.unesco.org/ark:/48223/pf0000372985

Vargo, S.L., \& Lusch, R.F. (2004). Evolving to a new dominant logic for marketing. Journal of marketing, 68(1), 1-17. https://doi.org/10.1509/jmkg.68.1.1.24036

Vargo, S.L., \& Lusch, R.F. (2008). Service-dominant logic: continuing the evolution. Journal of the Academy of marketing, 36, 1-10. https:// doi.org/10.1007/s11747-007-0069-6

Vargo, S.L., \& Lusch, R.F. (2017). Service-dominant logic 2025. International Journal of Research in Marketing, 34, 46-67. https://doi.org/10.1016/j.ijresmar.2016.11.001

WBCSD (2021). Circular Transition Indicators. Available at: https://www.wbcsd.org/Programs/Circular-Economy/Factor-10/Metrics-Measurement/Circular-transition-indicators

Webster, K. (2017). The circular economy: A wealth of flows. Ellen MacArthur Foundation Publishing.

Wooldridge, M. (2009). An introduction to multiagent systems. John Wiley \& Sons.

Journal of Industrial Engineering and Management, 2021 (www.jiem.org)

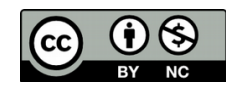

Article's contents are provided on an Attribution-Non Commercial 4.0 Creative commons International License. Readers are allowed to copy, distribute and communicate article's contents, provided the author's and Journal of Industrial Engineering and Management's names are included. It must not be used for commercial purposes. To see the complete license contents, please visit https://creativecommons.org/licenses/by-nc/4.0/. 